\title{
Dos diálogos de Fénelon sobre la pintura
}

\author{
Juan A. Calatrava Escobar
}

Presentamos a continuación la traducción castellana de dos textos estéticos escasamente conocidos de François Fénelon, quien, universalmente conocido como autor de Les Aventures de Telemaque o por sus posiciones políticas durante el reinado de Luis XIV, no dejó de ocuparse a lo largo de su dilatada trayectoria intelectual de los problemas artísticos contemporáneos. Los textos en cuestión son dos diálogos que tienen por tema a la pintura y que, en la línea del helenismo confeso de Fénelon, imitan claramente la estructura y el tono de un cierto género de diálogos literario-filosóficos griegos cuyo máximo exponente sería Luciano de Samosata y que pretenden reproducir imaginarias conversaciones, siempre de corte moralizante, celebradas en el Hades entre las almas de grandes personajes de la Historia. De hecho, los dos diálogos sobre la pintura fueron originalmente escritos para una obra de mayor envergadura, los Dialogues des Morts (1712), en los que se incluían diálogos con temáticas muy variadas pero casi siempre girando en torno a la misma problemática ética y a la reflexión política sobre la naturaleza del poder ya presente, como es bien conocido, en el Telemaque.

La clara unidad existente entre dos textos cuyos planteamientos estéticos son, como se verá, complementarios y no excluyentes ni reiterativos, llevó a que fueran objeto de una edición aparte que fue, de hecho, la que mayor difusión les otorgó entre los ambientes artísticos. Fueron publicados, en efecto, en 1730, como apéndice, junto con el poema de Molière a la Gloria de la Iglesia de Val-de-Grâce, a la biografía de Mignard del abate Monville ${ }^{1}$.

' (Monville, abbé de: La Vie de Pierre Mignard, Premier Peintre du Roi, avec le Poème de Molière sur les Peintures du Val-de-Grâce et Deux Dialogues de $M$. de Fenelon, Archevêque de Cambray, sur la Peinture, Paris, chez Jean Boudot et Jacques Gerin, 1730). 
Los dos diálogos tienen como protagonista central a N. Poussin, lo que implica ya una clara elección estética en las grandes polémicas que oponen a los ambientes artísticos franceses en la segunda mitad del siglo XVII y primeros del XVIII. Fénelon es un decidido poussinista, y el arte de Poussin constituye para él la perfecta ejemplificación de ese clasicismo nostálgico en el que las lecciones éticas que los hombres de la Antigüedad transmiten a la posteridad se desarrollan en el marco de una naturaleza arcádica, primitiva y al mismo tiempo -0 por éso mismoaúrea; un estado de ingenuidad pristina, de puro contacto con la naturaleza, que ha podido considerarse por numerosos estudiosos (Jacques Chouillet, por ejemplo) como pre-rousseauniano y al que apelaría el propio Fénelon desde el punto de vista lingüístico en su famosa Lettre à l'Académie ${ }^{2}$, su otro gran texto de implicaciones estéticas, aparecido en 1714.

Ambos textos constituyen, por otra parte, un magistral ejercicio de esa "ekfrasis" que tan grandemente había alimentado, desde el Renacimiento, la imaginación de artistas y teóricos que intuían la grandeza de la pintura griega pero que habian de contentarse con las descripciones literarias de Plinio, al no quedar restos materiales. Lo que Fénelon pone dos veces en boca de Poussin es la auténtica "ekfrasis» de dos de sus cuadros, destinada a explicar las características de su pintura a almas ciegas que vagan por el mundo de las sombras en una ignorancia semejante a la que los pintores modernos tienen respecto a la obra de Parrasio, Apeles o Zeuxis.

Precisamente es Parrasio el interlocutor de Poussin en el primero de los diálogos. El cuadro que sirve de eje al discurso es bien conocido en la producción poussiniana: el "Paisaje con los Funerales de Foción o Paisaje con el cuerpo de Foción llevado fuera de Atenas", actualmente en Prescott (Lancashire), col. Earl of Derby, y pintado en 1648 como «pendant» junto con otro cuadro de «La viuda de Foción recogiendo las cenizas de su marido". Félibien ${ }^{3}$ da informes más detallados sobre las circunstancias del encargo del cuadro, que figura con el número 173 en la catalogación de Anthonby Blunt ${ }^{4}$ y con el número 155 en la de Jacques Thuillier (L'opera completa di Poussin, Milán. Rizzoli, 1974). Blunt ${ }^{5}$ ha destacado muy bien las implicaciones éticas y filosóficas del tema: la

Ed. moderna en Ginebra, Droz, 1970.

Entretiens sur la vie et les ouvrages des plus excellens peintres, vol. IV, pág. 59.

The Paintings of Nicolas Poussin, Londres, Phaidon Press, 1966-67, 3 vols.; en el vol. de láminas lleva, sin embargo, el número 176.

5 Obra citada, vol. l, pág. 165 y ss. 
vida de Foción, como el conjunto de la obra de Plutarco, fue lectura favorita de Fénelon, que pretende ofrecernos, con la presencia de este héroe muerto del estoicismo en un paisaje arcádico, un mensaje de incorruptibilidad, austeridad y amor puro por la verdad. En cuanto a las implicaciones artísticas del diálogo, además de mostrarnos una clara exposición de los principios académicos sobre la construcción del paisaje, la teoría del contraste, etc., el verdadero tema del diálogo es la famosa "querelle des Anciens et des Modernes", en la que Fénelon trata de tomar un partido equilibrado, reconociendo en primer lugar lo absurdo de discutir la primacía de la pintura moderna o la antigua cuando no conocemos esta última, pero reafirmando, al mismo tiempo, la exigencia del estudio del Antiguo como fuente de toda belleza. Equilibrio éste que hace de Poussin, en el diálogo, un modelo de esa equitatividad buscada por el propio Fénelon en el seno de una "querelle" que, a la altura de 1712, comenzaba ya a aparecer para muchos como algo estéril.

En el segundo diálogo, el interlocutor de Poussin es Leonardo da Vinci y el cuadro parafraseado el «Paisaje con un hombre muerto por una serpiente" de la National Gallery de Londres, descubierto por Ellis Waterhouse ${ }^{6}$ en 1939. En este segundo diálogo el tono cambia rotundamente. Ya en el primero Parrasio se quejaba de los insufribles italianos que hacian imposible la vida en el Hades con sus continuas querellas. Ahora, Leonardo aparece como la muestra viva del orgullo irascible, la intolerancia y la soberbia que Fénelon atribuye a los pintores italianos. El tono prudente, mesurado y equitativo de Parrasio deja lugar a un Leonardo únicamente preocupado por comprobar si la obra de Poussin se ciñe a sus propias reglas de pintura, a las que considera universales. Así, pues, este diálogo aparece como inmediatamente complementario del primero: mientras que en aquél el tema primordial era la delimitación respectiva de los lugares en la historia de la pintura antigua y moderna, ahora se trata de comparar a las escuelas italiana y francesa. La conclusión es bien clara, y va en el sentido nacionalista que tan exhaustivamente ha estudiado Perouse de Montclos para el terreno de la arquitectura pero, que, con reservas y no tan generalizadamente, es trasplantable al terreno de la pintura: la idea de que los pintores franceses no son en modo alguno inferiores a los italianos ni han de sentir complejo de inferioridad, porque hombres como Poussin se han dedicado al único estudio posible para un pintor, el de la Antigüedad. Las palabras con que Poussin destruye finalmente la argumentación de Leonardo son total-

6 “Nicolas Poussin's Landscape with the Snake”, Burlington Magazine, LXXIV, 1939); número 209 del catálogo de Blunt y 159 del de Jacques Thuillier. 
mente significativas al respecto: "Sabed que no es ni en vuestros libros ni en los cuadros del siglo pasado donde yo me he instruido, sino en los bajorrelieves antiguos, en los que vos habéis estudiado tanto como yo".

\section{DIÁLOGOS SOBRE LA PINTURA}

\section{PARRASIO Y POUSSIN}

Par: Hace ya largo tiempo que se hacía esperar vuestra llegada; es preciso que hayáis muerto bastante viejo.

Pous: Así es, y he trabajado hasta una edad muy avanzada.

Par: Se os ha asignado aquí un rango bastante honorable a la cabeza de los pintores franceses; si os hubiesen colocado entre los italianos hubieseis estado en mejor compañia. Pero estos pintores, que Vasari nos alaba todos los días, os habrían planteado muchas querellas. Hay dos escuelas, la lombarda y la florentina, por no hablar de la que en seguida se formó en Roma. Todas esas gentes nos rompen la cabeza sin cesar con sus celos. Nos habían tomado como jueces de sus diferencias a Apeles, a Zeuxis y a mí. Pero habriamos tenido más trabajo que Minos, Eaque y Radamante si hubiésemos pretendido ponerlos de acuerdo. Están celosos incluso de los Antiguos y osan compararse a nosotros. Su vanidad es insoportable.

Pous: No hay que comparar, puesto que vuestras obras no permanecen para permitir un juicio, y no creo que hayáis realizado otras nuevas a orillas de la Estigia. Está demasiado oscuro para sobresalir en el colorido, en la perspectiva y en la degradación de la luz. Un cuadro hecho aquí abajo no podría ser sino una escena nocturna ("une nuit»); todo él sería sombrío. Para volver a vosotros, Antiguos, convengo en que el prejuicio general está a vuestro favor. Hay motivos para creer que vuestro arte, que es del mismo gusto que la Escultura, haya sido llevado a similar perfección y que vuestros cuadros igualen las estatuas de Praxiteles, Scopas y Fidias; pero, en fin, no nos queda nada vuestro y la comparación es imposible. Por éso estáis fuera de todo alcance y nos mantenéis a raya. Lo que sí es verdad es que nosotros pintores modernos, debemos nuestras mejores obras a los modelos antiguos que hemos estudiado en los bajorrelieves. Dichos bajorrelieves, aunque pertenecen a la Escultura, 
dejan comprender, en buena medida, con qué gusto se debía pintar en aquel tiempo. Son una semi-pintura («demie peinture»).

Par: Estoy encantado de encontrar un pintor moderno tan equitativo $y$ tan modesto. Comprenderéis que cuando Zeuxis hizo uvas que engañaban a los pájaros fue preciso que la naturaleza estuviese bien imitada para engañar a la naturaleza misma. $Y$ cuando yo pinté después una cortina que engañó a ios ojos, tan hábiles, del gran Zeuxis, se confesó vencido. Ved hasta que extremos hemos impulsado este bello error. No, no, no es por nada por lo que todos los siglos nos han alabado. Pero decidme algo de vuestras obras. Le han dicho aquí a Foción que vos habiais realizado bellos cuadros en los que él está representado. Esta noticia le ha alegrado. ¿Es cierta?

Pous: Indudablemente. He representado su cuerpo, al que dos esclavos llevan fuera de la ciudad de Atenas. Parecen ambos afligidos y sus dolores no se asemejan en nada. El primero de estos esclavos es viejo; está envuelto en un paño corriente y el desnudo de brazos y piernas nos muestra a un hombre fuerte y nervudo; es una carnación que marca un cuerpo endurecido en el trabajo. El otro es joven, cubierto con una túnica que hace pliegues bastante graciosos; las dos actitudes son diferentes en la misma acción y los dos aires de las cabezas son muy variados, aunque ambos sean serviles.

Par: Bueno, el arte no imita bien a la naturaleza más que en tanto que atrapa en sus obras esa infinita variedad. Pero el muerto...

Pous: El muerto está oculto bajo un paño confuso que lo envuelve; es un paño corriente y pobre. En este cortejo todo es susceptible de excitar la piedad y el dolor.

Par: ¿No se ve al muerto?

Pous: No deja de apreciarse, bajo ese drapeado confuso, la forma de la cabeza y de todo el cuerpo. Por lo que respecta a las piernas, están descubiertas. Se puede apreciar en ellas no sólo el color marchito de la carne muerta sino también la rigidez y la pesadez de los miembros desplomados. Estos dos esclavos, que portan el cuerpo a lo largo de un gran camino, encuentran al lado de éste grandes piedras talladas en cuadrado, algunas de las cuales se alzan ordenadamente por encima de otras, de suerte que se cree ver las ruinas de algún majestuoso edificio. El camino parece arenoso y pisado.

Par: ¿Qué habéis puesto a ambos lados de este cuadro para acompañar a vuestras figuras principales? 
Pous: En el lado derecho hay dos o tres árboles cuyo tronco es de una corteza áspera y nudosa. Tienen pocas ramas, cuyo verde, que es un tanto débil, se pierde insensiblemente en la sombra azul del cielo. Tras estos largos troncos se ve la ciudad de Atenas.

Par: Hace falta un contraste bien marcado en el lado izquierdo.

Pous: Helo aquí. Es un terreno desigual; se aprecian en él hondonadas que están en una sombra muy fuerte y puntas de roca muy iluminadas. Se presentan también algunos matorrales bastante salvajes. Un poco por encima hay un camino que lleva a un bosque sombrío y denso y un cielo extremadamente claro da aún más fuerza a este verdor sombrio.

Par: Bueno, he ahí lo que está bien. Veo que conocéis el gran arte de los colores, que consiste en fortalecer al uno por su oposición con el otro.

Pous: Más allá de este terreno rudo se nos presenta una hierba fresca y tierna. Se distingue en ella a un pastor apoyado sobre su cayado y ocupado en mirar a sus corderos, blancos como la nieve, que vagan paciendo en un prado. El perro del pastor está tendido y duerme tras él. En este campo se ve otro camino por el que pasa una carreta tirada por bueyes. Notáis, en primer lugar, la fuerza y pesadez de estos animales, cuyo cuello está inclinado hacia el suelo y que marchan a paso lento. Un hombre de aspecto rústico está delante de la carreta; una mujer marcha detrás y parece la fiel compañera de este simple aldeano. Otras mujeres, con velos, están sobre la carreta.

Par: Nada produce un placer más sensible que estas pinturas campestres. Las debemos a los poetas. Comenzaron a cantar en sus versos las gracias ingenuas de la naturaleza simple y sin arte. Nosotros los hemos seguido. Los ornamentos de un campo en el que la naturaleza es bella son una imagen más riente que todas las magnificencias que el arte haya podido inventar.

Pous: Se ve en este camino, al lado derecho, sobre un caballo alazán, a un caballero envuelto en un manto rojo. Caballero y caballo están inclinados hacia adelante. Parecen abalanzarse para correr con más rapidez. Las crines del caballo, los cabellos del hombre, su manto, todo está flotante y empujado hacia atrás por el viento.

Par: Los que no saben sino representar figuras graciosas no han alcanzado más que el género mediocre. Hay que pintar la acción y el movimiento, animar las figuras y expresar las pasiones del alma. Veo que habéis penetrado bien en el gusto de la antigüedad. 
Pous: Más adelante se aprecia un césped bajo el que aparece un terreno arenoso, y tres figuras humanas están sobre esta hierba. Una de ellas está de pie, cubierta con un manto blanco de grandes pliegues flotantes. Las otras dos están sentadas cerca de aquél, al borde del agua, y una de ellas toca la lira. Sobre este terreno cubierto de hierba se ve un edificio cuadrado, ornado con bajorrelieves y festones, de un buen gusto de Arquitectura simple y noble. Es, sin duda, una tumba de algún ciudadano muerto quizás con menos virtud pero con más fortuna que Foción.

Par: No olvido que habéis hablado del borde del agua. ¿Se trata del río de Atenas, llamado llisso?

Pous: Sí, aparece en dos lugares a los lados de esta tumba y es de un agua pura y clara. El cielo sereno que está pintado en este agua sirve para hacerla aún más bella. Está bordeada de sauces nacientes y otros arbustos tiernos cuyo frescor alegra la vista.

Par: Hasta el momento no me queda nada que desear. Pero aún tenéis que representarme un gran y difícil objeto, y es ahí donde os espero.

Pous: ¿Cuál?

Par: La ciudad. Es ahi donde debéis demostrar que conocéis la Historia, le Costume, la Arquitectura.

Pous: He pintado esta gran ciudad de Atenas bajo la pendiente de una larga loma para mejor hacerla ver. Los edificios se encuentran allí por grados en un anfiteatro natural; esta ciudad no parece grande al primer vistazo. Uno no ve cerca de sí más que un trozo bastante mediocre. Por la parte de atrás, que huye, descubre una gran extensión de edificios.

Par: ¿Habéis evitado la confusión en ellos?

Pous: He evitado la confusión y la simetria. He hecho muchos edificios irregulares. Pero no dejan de formar una reunión graciosa en la que cada cosa ocupa su lugar más natural. Todo destaca y se distingue sin esfuerzo. Todo se une y forma cuerpo. Así, hay una confusión aparente y un orden verdadero cuando se observa de cerca.

Par: ¿No habéis colocado en la parte frontal algún edificio principal?

Pous: He situado alli dos templos. Cada uno tiene un gran recinto, como debían tenerlo, en el que se distingue el cuerpo del templo de los otros edificios que lo acompañan. El templo que está a mano derecha tiene una portada ornada con cuatro grandes columnas de orden corintio, 
con un frontón y estatuas. En torno a este templo se ven festones pendientes: se trata de una fiesta que he querido representar según la verdad de la historia. Mientras que se llevan a Foción fuera de la ciudad, a la pira, todo el pueblo, con alegría y pompa, hace una gran solemnidad en torno al templo de que os hablo. Aunque este pueblo se nos muestra bastante lejos, no deja de notarse sin esfuerzo una acción de alegría para honrar a los dioses. Tras este templo aparece una gruesa torre muy alta en cuya cúspide hay una estatua de alguna divinidad. Esta torre es como una gruesa columna.

Par: ¿De dónde habéis tomado esta idea?

Pous: No lo recuerdo. Pero seguramente está tomada del antiguo, porque yo nunca me he tomado la libertad de dar a la antigüedad nada que no esté sacado de sus monumentos. Se ve también cerca de esta torre un obelisco.

Par: $Y$ del otro templo, ¿no decís nada?

Pous: Este otro templo es un edificio redondo, sostenido por columnas; su arquitectura parece majestuosa y singular. En su recinto se aprecian diversos grandes edificios con frontones. Algunos árboles ocultan una parte a la vista. He querido indicar un bosque sagrado.

Par: Pero vayamos al cuerpo de la ciudad.

Pous: He creído deber marcar en él los diversos momentos de la República de Atenas, su primera simplicidad, a remontar a los tiempos heroicos, y su magnificencia en los siglos siguientes, en los que las artes florecieron en ella. Así, he realizado muchos edificios redondos o cuadrados, con una arquitectura regular, y muchos otros que dejan sentir esta antigüedad rústica y guerrera. Todo en ellos es de una figura extraña. No se ven más que torres, almenas, altas murallas, pequeños edificios desiguales y simples. Una cosa hace a esta ciudad agradable, y es que todo en ella está entremezclado de edificios y sotos. He creído que había que colocar verdor por todas partes para representar los bosques sagrados de los templos y los árboles que habia tanto en los gimnasios como los otros edificios públicos. He intentado evitar hacer construcciones que tuviesen relación con las de mi tiempo y mi pais para dar a la antigüedad un carácter fácil de reconocer.

Par: Todo éso está juiciosamente observado, pero no veo la Acrópolis. ¿La habéis olvidado? Sería una pena.

Pous: No la descuidé. Se encuentra detrás de toda la ciudad, en la cima de la montaña que domina la loma en pendiente. Se ven a sus pies 
grandes edificios rodeados por torres. La montaña está cubierta por un agradable verdor. Para la Ciudadela, se nos muestra un recinto bastante grande con una vieja torre que se eleva hasta las nubes. Notaréis que la ciudad, que se ve siempre descendiendo hacia el lado izquierdo, se aleja insensiblemente y se pierde entre un bosque muy sombrío, del que ya os he hablado, y un bosquecillo de otros árboles, de un verde oscuro y profundo, que se encuentra al borde del agua.

Par: Aún no estoy satisfecho. ¿Qué habéis colocado detrás de toda esta ciudad?

Pous: Una lejanía en la que se distinguen montañas escarpadas y bastante salvajes. Hay una detrás de esos bellos templos y esa pompa tan riente de que os he hablado, que es una roca totalmente desnuda y espantosa. Me ha parecido que debía representar el entorno de la ciudad cultivado y gracioso, como lo es siempre el de las grandes ciudades. Pero he dado una cierta belleza salvaje a la lejanía para conformarme a la Historia, que habla del Atica como de un país rudo y estéril.

Par: Confieso que mi curiosidad está bien satisfecha, y estaría celoso por la gloria de la Antigüedad si se pudiera estarlo de un hombre que la ha imitado tan modestamente.

Pous: Acordaos, al menos, de que, si os he entretenido largo tiempo con mi obra, lo he hecho para no rehusaros nada y para someterme a vuestro juicio.

Par: Después de tantos siglos, habéis hecho más honor a Foción del que su patria habría podido hacerle con suntuosos funerales en el día de su muerte. Pero vayamos a este jardín de aquí cerca, donde se encuentra con Timoleón y Arístides, para informarle de tan agradables noticias.

\section{LEONARDO DA VINCI Y POUSSIN}

Leo: Vuestra conversación con Parrasio está dando mucho que hablar en este bajo mundo. Se asegura que él está prevenido en vuestro favor, y que os pone por encima de todos los pintores italianos. Pero nosotros no lo soportaremos jamás...

Pous: ¿Tan fácil de prevenir lo creéis? Sois injusto con él, lo sois con vos mismo y me hacéis a mí demasiado honor. 
Leo: Pero me ha dicho que no conoce nada tan bello como el cuadro que le habéis representado. ¿Con qué propósito ofender a tantos grandes hombres para alabar a uno solo que...?

Pous: Pero, ¿por qué creéis que se os ofende cuando se alaba a otros? Parrasio no ha establecido comparación. ¿De qué os quejáis?

Leo: Si, verdaderamente, un pequeño pintor francés que se vio obligado a abandonar su patria para ir a ganarse la vida en Roma.

Pous: ${ }_{\mathrm{H}} \mathrm{Ho}$ ! Puesto que la emprendéis por ese camino, no tendréis la última palabra. $Y$ bien, es cierto: para ir a vivir a Roma, donde yo habia estudiado los modelos antiguos y donde la Pintura era más honrada que en mi país. Pero, aunque extranjero, yo era admirado en Roma. $Y$ vos, que eráis italiano, ¿acaso no os visteis obligado a abandonar vuestro país, aunque la pintura gozase en él de tanta honra, para ir a morir a la corte de Francisco I?

Leo: Quisiera examinar un poco alguno de vuestros cuadros según las reglas de Pintura que he explicado en mis libros. Se apreciarían tantos defectos como pinceladas.

Pous: Consiento en ello, y quiero creer que no soy tan gran pintor como vos, pero sí menos celoso de mis obras. Voy a poneros ante la vista toda la ordenación ("ordonnance») de uno de mis cuadros. Si apreciáis faltas en él, las confesaré con franqueza; si aprobáis lo que hecho, os obligaré a estimarme un poco más de lo que lo hacéis.

Leo: Pues bien, veamos. Pero yo soy un crítico severo, recordadlo.

Pous: Tanto mejor. Imagináos una roca que está en el lado izquierdo del cuadro. De esta roca mana una fuente de agua pura y clara que, tras haber hecho algunos pequeños borbotones en su caida, escapa a través del campo. Un hombre que había venido a tomar de esta agua se ve sorprendido por una serpiente monstruosa. La serpiente se enrosca en torno a su cuerpo y entrelaza sus brazos y sus piernas en varias vueltas. lo aprieta, lo empozoña con su veneno y lo asfixia. Ese hombre está ya muerto. Está tendido. Se aprecia la pesadez y la rigidez de todos sus miembros. Su carne está ya lívida. Su espantoso rostro refleja una muerte cruel.

Leo: Si nos presentáis otro objeto, he ahí un cuadro bien triste.

Pous: Vais a ver algo que aumente aún esta tristeza. Se trata de otro hombre que avanza hacia la fuente y se apercibe de la serpiente alrededor del hombre muerto. Se detiene repentinamente. Uno de sus pies permanece suspendido. Levanta un brazo mientras que el otro cae 
hacia abajo. Pero las dos manos se abren; marcan la sorpresa y el horror.

Leo: Ese segundo objeto, aunque triste, no deja de animar el cuadro y de producir un cierto placer similar a los que experimentaban los espectadores de esas antiguas tragedias en las que todo inspiraba terror $y$ piedad; pero pronto veremos si habéis...

Pous: ¡Ah, ah! Comenzáis a humanizaros un poco. Pero esperad, si os place, la continuación, y juzgaréis según vuestras reglas cuando yo lo haya dicho todo. Cerca hay un gran camino, al borde del cual aparece una mujer que ve al hombre espantado pero que no puede ver al hombre muerto porque está en una hondonada y el terreno hace una especie de cortina entre ella y la fuente. La visión de este hombre espantado produce en ella un contragolpe de terror. Estos dos espantos son, como se suele decir, lo que deben ser los dolores, que los grandes se callan y de los pequeños se queja uno. El espanto del hombre lo inmoviliza; el de la mujer, que es menor, está más marcado por la mueca de su rostro. Se ve en ella un miedo de mujer que nada puede retener, que expresa toda su alarma, que se deja llevar por lo que siente; cae sentada, se deja caer y olvida lo que lleva; exitende los brazos y parece gritar. ¿No es verdad que estos diversos grados de temor y sorpresa son una especie de juego que conmueve y que place?

Leo: Convengo en ello. Pero, ¿qué diseño es éste? ¿Se trata de una historia? Yo no la conozco. Es más bien un capricho...

Pous: Es un capricho. Este tipo de obras nos llega muy bien siempre que el capricho esté reglado y no se aparte en nada de la verdadera naturaleza. Se ven en el lado izquierdo algunos grandes árboles que parecen viejos, tales como esos antiguos robles que en otro tiempo pasaban por ser las divinidades de un país. Sus troncos venerables tienen una corteza ruda y áspera que hace retroceder a un seto tierno y naciente que hay detrás. Este seto tiene un frescor delicioso. Uno querria estar alli. Nos imaginamos un ardiente verano que respeta este bosque sagrado. Está plantado a lo largo de un agua clara en la que parece mirarse. Se ve a un lado un verde profundo y al otro un agua pura en la que se descubre la sombra azul de un cielo sereno. En este agua se presentan diversos objetos que distraen la vista para que descanse de todo lo espantoso que ha visto. En la parte de delante del cuadro todas las figuras son trágicas. Pero en este fondo todo es apacible, dulce y riente: se ven jóvenes que se bañan y que se ejercitan nadando; más allá, pescadores en un bote. Uno se inclina hacia adelante y parece a punto de caer: y es que sacan la red. Otros dos, inclinados hacia atrás, 
reman con esfuerzo. Otros están a la orilla del agua y juegan a la morra. Se ve en sus rostros que uno piensa en un número para sorprender a su compañero, que se muestra atento por miedo a ser sorprendido. Otros se pasean, más allá de este agua, sobre una hierba fresca y tierna. Viéndolos en un lugar tan bello, poco falta para que envidiemos su felicidad. Se ve, bastante lejos, a una mujer que va, a lomos de un asno, a la ciudad vecina, y que es seguida por dos hombres. $Y$ en seguida uno imagina ver a esas buenas gentes que, en su simplicidad rústica, van a llevar a las ciudades la abundancia de los campos que han cultivado. En la misma esquina izquierda aparece, por encima del soto, una montaña bastante escarpada sobre la cual hay un castillo.

Leo: El lado izquierdo de vuestro cuadro me despierta la curiosidad por ver el derecho.

Pous: Se trata de una pequeña colina que va en pendiente casi insensible hasta la orilla del río. Sobre esta pendiente se distinguen, en confusión, arbustos y zarzas sobre un terreno inculto. Delante de esta colina están plantados grandes árboles entre los cuales se percibe el campo, el agua y el cielo.

Leo: Pero el cielo, ¿cómo lo habéis hecho?

Pous: Es de un bello azul, mezclado con nubes claras que parecen ser de oro y plata.

Leo: Lo habéis hecho así, sin duda, para tener la libertad de disponer a vuestro antojo de la luz y extenderla sobre cada objeto según vuestros designios.

Pous: Lo confieso. Pero vos debéis confesar, igualmente, que parece, por ello, que yo no ignoro vuestras reglas, de las que tanto os enorgullecéis.

Leo: ¿Qué hay en el centro de este cuadro, más allá del río?

Pous: Una ciudad de la que ya he hablado. Se encuentra en una hondonada en la que se pierde; una colina llena de verdor nos oculta una parte. Se ven viejas torres, almenas, grandes edificios y una confusión de casas en una sombra muy fuerte; lo que destaca algunos lugares iluminados por una cierta luz dulce y viva que viene de arriba. Por encima de esta ciudad aparece lo que se ve casi siempre sobre las ciudades con buen tiempo. Es un humo que se eleva y hace retroceder a las montañas que hay en la lejania. Estas montañas, de rara figura, hacen variar el horizonte de tal suerte que los ojos quedan contentos. 
Leo: Este cuadro del que me habláis me parece menos sabio que el de Foción.

Pous: Hay menos ciencia de la arquitectura, es verdad. Por lo demás, no se ve en él ningún conocimiento de la antigüedad. Pero, en cambio, la ciencia de expresar las pasiones es en él bastante grande. Además, todo este paisaje posee gracias y una ternura que el otro no igualaba.

Leo: ¿Os decidiríais, pues, por este cuadro?

Pous: Lo prefiero, sin dudarlo. Pero vos, ¿qué pensáis sobre mi relación?

Leo: No conozco el cuadro de Foción lo suficiente como para comparar. Veo que habéis estudiado los buenos modelos del siglo pasado y mis libros. Pero alabáis en demasia vuestras obras.

Pous: Sois vos quien me ha obligado a hablar de ello. Pero sabed que no es ni en vuestros libros ni en los cuadros del siglo pasado donde me he instruido, sino en los bajorrelieves antiguos, en los que vos habéis estudiado tanto como yo. Si pudiera algún día volver entre los vivos, pintaría los celos, porque vos me habéis proporcionado aquí excelentes modelos. Por mi parte, no pretendo quitaros nada de vuestra ciencia ni de vuestra gloria; pero cedería ante vos con mucho más placer si estuvieseis menos imbuido de vuestro rango. Vamos a buscar a Parrasio. Le haréis vuestra crítica y él decidirá, si os parece; porque yo no cedo ante vosotros, Señores Modernos, sino a condición de que vosotros cedáis ante los Antiguos. Una vez que Parrasio se haya pronunciado, estaré dispuesto a volver a la tierra para corregir mi cuadro. 